\title{
Ekstraksi Emas dari Limbah Papan Sirkuit Telepon Genggam Menggunakan Teknik Membran Cair Emulsi
}

\author{
Imam Santoso, Silvana Tatian, Irma Ratna Kartika dan Tritiyatma H \\ Jurusan Kimia FMIPA Universitas Negeri Jakarta
}

\begin{abstract}
Abstrak
Penelitian ini bertujuan untuk menentukan persen ekstraksi emas dari limbah papan sirkuit telepon genggam dengan teknik membran cair emulsi menggunakan MIBK sebagai carrier. Reaksinya terjadi secara simultan di permukaan membran, antara senyawa yang akan dipisahkan pada fasa umpan dengan senyawa pembawa pada fasa organik. Logam emas hasil reaksi akan terdifusi ke fasa membran yang pada akhirnya hasil ekstraksi terkumpul dan terkonsentrasi di fasa penerima. Sebelum diaplikasikan ke limbah telepon, terlebih dahulu dipelajari beberapa parameter yang berpengaruh terhadap perolehan persen ekstraksi. Pada penelitian ini kondisi optimum untuk parameter pembuatan fasa emulsi yaitu 1:1, pengaruh kecepatan pembuatan emulsi pada yaitu 1000 rpm.Pengaruh konsentrasi carrier terhadap persen ekstraksi emas dengan konsentrasi MIBK sebesar 3\%, pengaruh kecepatan kontak terhadap persen ekstraksi emas adalah pada $1000 \mathrm{rpm}$. Penerapan kondisi optimum pada limbah papan sirkuit telepon genggam memberikan persen ekstraksi Au sebesar 83.24\%.
\end{abstract}

Kata Kunci: limbah papan sirkuit telepon genggam, MIBK, teknik membran cair emulsi.

\begin{abstract}
Abstrack
This research aim is to determine extraction percentage of gold from cellular phone circuit board waste using emulsion liquid membrane technique with Methyl Isobutyl Ketone (MIBK) as carrier. The reaction occur simultaneously on the membrane surface, between compound going to be separate in feed phase with carrier compound in organic phase. Gold from reaction will diffuse into membrane phase which finally will be collected and concentrated in receiving phase. Before it applied to phone waste, there are several parameters studied which influence the extraction percentage result. In this research the optimum condition for building emulsion phase parameter is $1: 1$, effect on building emulsion rate is $1000 \mathrm{rpm}$. Carrier concentration effect to extraction percentage of gold is at 3\% MIBK and contact rate effect is at $1000 \mathrm{rpm}$. Optimum condition application to cellular phone circuit board waste give Au extraction percentage of $83.24 \%$.
\end{abstract}

Keywords: cellular phone circuit board waste, MIBK, emulsion liquid membrane technique.

\section{PENDAHULUAN}

Emas atau Aurum (Au) adalah logam yang bernilai sejak peradaban manusia. Emas memiliki konduktivitas panas dan listrik yang baik serta tidak bereaksi atau terkorosi oleh udara dan bahan lainnya. Oleh karena itu, emas dijadikan mata uang koin dan standar keuangan dibanyak negara. Selain itu emas juga digunakan sebagai perhiasan, dekorasi, untuk melapisi logam lain dan bahan tambalan gigi dibidang kedokteran (Sugiarto, 2010).

Emas yang dipergunakan biasanya diperoleh dari hasil pertambangan. Namun, emas merupakan sumber daya alam yang tidak dapat diperbaharui sehingga manusia berupaya mencari alternatif lain yaitu memanfaatkan emas dari limbah. Salah satu limbah yang banyak mengandung emas adalah limbah telepon genggam. Semakin hari perkembangan 
teknologi telepon genggam semakin maju, hal ini berdampak pada peningkatan limbah telepon genggam. Apabila limbah telepon genggam ini dimanfaatkan tentunya akan mengurangi pencemaran. Selain itu, limbah telepon genggam mudah diperoleh dan harganya lebih murah dibandingkan dengan bebatuan yang mengandung logam emas (Sofyan, 2010).

Metode pemisahan emas yang biasa digunakan adalah amalgamasi dan sianidasi. Amalgamasi adalah proses pengikatan logam emas dari bijih menggunakan merkuri (Widodo, 2008). Sianidasi merupakan proses pelarutan selektif oleh asam sianida dimana hanya logamlogam tertentu yang dapat larut, misalnya $\mathrm{Au}$, $\mathrm{Ag}, \mathrm{Cu}, \mathrm{Zn}, \mathrm{Cd}$ dan Co (Guzman, 1999). Metode amalgamasi dan sianidasi menimbulkan berbagai permasalahan, antara lain pemborosan sumber daya mineral karena banyak logam emas dan residu yang terbuang seingga tingkat perolehan (recovery) logam emas rendah.Disamping itu terjadi degradasi lingkungan yang disebabkan oleh pembuangan sisa merkuri dan sianida ke perairan.

Metode amalgamasi dan sianidasi kurang menguntungkan dari segi ekonomi, lingkungan dan kesehatan, sehingga digunakan teknik baru untuk pemisahan emas yaitu teknik membran cair emulsi.Teknik membran cair emulsi merupakan teknik yang potensial dan efektif dalam proses pemisahan emas. Reaksi terjadi secara simultan di permukaan membran, antara senyawa yang akan dipisahkan yang berada di fasa umpan dengan senyawa pembawa pada fasa organik. Logam emas hasil reaksi akan terdifusi ke fasa membran yang pada akhirnya hasil ekstraksi terkumpul dan terkonsentrasi di fasa penerima. Ekstraksi berjalan sangat cepat karena tebal lapisan membran yang dilewati sangat tipis dan luas permukaan yang besar per unit volume (Mok et al., 1997).

Mekanisme transpor ekstraksi dan reekstraksi didasarkan pada jenis reaksi penukaran ion antara emas dengan carrier metil isobutil keton. MIBK yang terlarut dalam fasa membran bereaksi dengan ion $\mathrm{AuCl}_{4}^{-}$dan proton $\mathrm{H}^{+}$menghasilkan spesi $\mathrm{AuCl}_{4}-\mathrm{MIBK}$, di permukaan antara fasa membran dengan fasa eksternal.

$$
\mathrm{MIBK}_{(\text {org })}+\mathrm{H}_{\text {(org) }}^{+}+\mathrm{AuCl}_{4^{-}} \text {(aq) } \longrightarrow \mathrm{AuCl}_{4^{-}}-\mathrm{MIBK}_{\text {(org) }}
$$

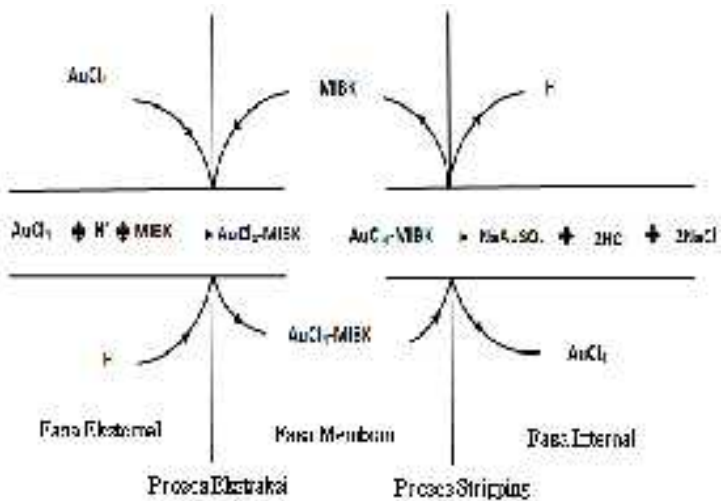

Gambar 1. Skema proses transpor emas melalui membran cair emulsi (Coelhoso, 1995)

Spesi $\mathrm{AuCl}_{4}$-MIBK terdifusi ke fasa membran, kemudian ion $\mathrm{AuCl}_{4^{-}}$dan ion $\mathrm{H}^{+}$ terlepas masuk ke fasa penerima.Terlepas dan masuknya ion $\mathrm{AuCl}_{4^{-}}$serta ion $\mathrm{H}^{+}$ke fasa internal disebabkan oleh gradien konsentrasi emas.Senyawa carrier yang telah melepaskan ion $\mathrm{AuCl}_{4^{-}}$dan $\mathrm{H}^{+}$, kembali ke permukaan fasa membran. Secara keseluruhan proses transpor berpasangan difusi ion $\mathrm{AuCl}_{4^{-}}$dan $\mathrm{H}^{+}$dari fasa eksternal ke fasa internal (proses pelucutan/stripping) (gambar 1).

Untuk mengetahui kadar emas hasil ekstraksi, digunakan rumus sebagai berikut :

$$
\% \text { Ekstraksi Emus }=\frac{\text { [Aujmula-mula }- \text { LAujasa }}{\text { |Aulmula-mula }} \times 100 \%
$$

\section{METODE PENELITIAN}

\section{Alat dan Bahan}

Alat yang digunakan pada penelitian ini adalah pengaduk magnet, ultrasonik HPLC, mikro pipet, $\mathrm{pH}$ meter, corong pisah, satu set spektrofotometer serapan atom dan alat-alat gelas yang biasa digunakan dalam laboratorium kimia. 
Bahan yang digunakan dalam penelitian ini terdiri dari $\mathrm{AuCl}_{4}$ dari Merck kondisi PA, limbah papan sirkuit telepon genggam, aquades, metil isobutil keton (MIBK) kondisi PA dari Merck, span 80 dari sigma, Natrium Hidroksida $(\mathrm{NaOH})$ kondisi PA, Natrium Sulfit $\left(\mathrm{Na}_{2} \mathrm{SO}_{3}\right)$ kondisi PA, Asam Klorida pekat $(\mathrm{HCl})$ kondisi PA dan paraffin kondisi PA (Sigma).

\section{Pembuatan Kurva Kalibrasi}

Sebanyak 6,25 mL larutan asam aurat klorida $1.000 \mathrm{ppm}$ dimasukkan ke dalam labu ukur $250 \mathrm{~mL}$, lalu diencerkan hingga tanda batas. Setelah itu diperoleh larutan induk emas $25 \mathrm{ppm}$. Kemudian, larutan induk diencerkan menjadi $1,0 \mathrm{ppm}, 2,0 \mathrm{ppm}, 3,0 \mathrm{ppm}, 4,0 \mathrm{ppm}$, 5,0 ppm, 6,0 ppm, 8,0 ppm dan $10 \mathrm{ppm}$. Lalu, diukur absorbansinya menggunakan spektrofotometer serapan atom pada panjang gelombang maksimal 242,8 nm. Setelah itu, dibuat kurva kalibrasi antara absorbansi dengan konsentrasi larutan standar emas.

\section{Penentuan Kondisi Optimum}

a. Pengujian Kestabilan Emulsi

1) Pembuatan fasa emulsi $1: 1$

Sebanyak $5 \mathrm{~mL}$ fasa membran yang terdiri dari: $0.5 \mathrm{~mL}$ Span $80 ; 5.0 \mathrm{~mL}$ paraffin dimasukkan ke dalam gelas kimia $50 \mathrm{~mL}$. Kemudian, fasa membran dicampurkan dengan $5 \mathrm{~mL}$ fasa internal yang terdiri dari natrium hidroksida $0.4 \mathrm{M}$ dan natrium sulfit $0.4 \mathrm{M} \mathrm{pH}=$ 2. Setelah itu, campuran diaduk menggunakan magnetik stirrer dengan kecepatan 500 rpm selama 5 menit.

\section{2). Pembuatan fasa emulsi $1: 2$}

Sebanyak $10 \mathrm{~mL}$ fasa membran yang terdiri dari: $0.75 \mathrm{~mL}$ Span $80 ; 10 \mathrm{~mL}$ paraffin dimasukkan ke dalam gelas kimia $50 \mathrm{~mL}$. Kemudian, fasa membran dicampurkan dengan $5 \mathrm{~mL}$ fasa internal yang terdiri dari: natrium hidroksida $0.4 \mathrm{M}$ dan natrium sulfit $0.4 \mathrm{M}$. Setelah itu, campuran diaduk menggunakan magnetik stirrer dengan kecepatan 500rpm selama 5 menit.

\section{3). Pembuatan fasa emulsi 2 : 1}

Sebanyak $5 \mathrm{~mL}$ fasa membran yang terdiri dari: $0.5 \mathrm{~mL}$ Span $80 ; 5.0 \mathrm{~mL}$ paraffin dimasukkan ke dalam gelas kimia $50 \mathrm{~mL}$. Lalu, fasa membran dicampurkan dengan $10 \mathrm{~mL}$ fasa internal yang terdiri dari: natrium hidroksida 0.4 $\mathrm{M}$ dan natrium sulfit $0.4 \mathrm{M}$. Setelah itu, campuran diaduk menggunakan magnetik stirrer dengan kecepatan 500 rpm selama 5 menit.

\section{b. Pengaruh Kecepatan Pengadukan Pembuatan Emulsi Terhadap Kestabilan Emulsi}

Emulsi yang memiliki kestabilan paling tinggi dibuat dengan kecepatan pengadukan 200 rpm, $400 \mathrm{rpm}, 600 \mathrm{rpm}, 800 \mathrm{rpm}$ dan $1000 \mathrm{rpm}$. Tentukan tinggi emulsi setiap $0,5,10,15,20$, 25, 30, 35, 40 dan 45 menit.Tentukan kecepatan yang menunjukkan kondisi emulsi yang stabil.

\section{c. Pengaruh Konsentrasi Carrier Terhadap Persen Ekstraksi Emas}

Emulsi yang memiliki kestabilan paling baik dengan kecepatan paling optimal ditambahkan dengan carrier MIBK 1\%, 2\%, $3 \%$, 4\% dan 5\%.Campurkan emulsi dengan 20 $\mathrm{mL}$ fasa eksternal yang mengandung $25 \mathrm{ppm}$ emas.Lakukan pengadukan dengan kecepatan kontak $500 \mathrm{rpm}$ selama 5 menit.Biarkan emulsi terpisah dari fasa eksternal.Tentukan konsentrasi fasa eksternal dengan spektrofotometri serapan atom.Lalu, hitung persen ekstraksi emas.Tentukan konsentrasi carrier optimal.

\section{d. Pengaruh Kecepatan Kontak Terhadap Persen Ekstraksi Emas}

Emulsi yang memiliki kestabilan paling baik dengan kecepatan paling optimal dan konsentrasi carrier MIBK paling optimaldicampurkan dengan $20 \mathrm{~mL}$ fasa eksternal yang mengandung $25 \mathrm{ppm}$ emas. Lakukan pengadukan dengan kecepatan kontak $200 \mathrm{rpm}, 400 \mathrm{rpm}, 600 \mathrm{rpm}, 800 \mathrm{rpm}$ dan 1000 rpm selama 5 menit. Biarkan emulsi terpisah dari fasa eksternal.Tentukan konsentrasi fasa eksternal dengan spektrofotometri serapan atom.Tentukan keceparan kontak optimal. 


\section{Penerapan Kondisi Optimum pada Limbah Papan Sirkuit Telepon Genggam}

Timbang limbah telepon genggam yang mengandung emas.Lakukan destruksi dengan aqua regia, panaskan hingga hampir kering, tambahkan $25 \mathrm{~mL} \mathrm{HCl}$, lalu panaskan kembali selama 10 menit. Saring dengan akuades hangat $50 \mathrm{~mL}$, tentukan konsentrasi filtrat dengan SSA.Lakukan kontak dengan emulsi sesuai kondisi optimum.Biarkan emulsi terpisah dari fasa eksternal.Tentukan konsentrasi fasa eksternal dengan spektrofotometri serapan atom.Lakukan pemecahan fasa emulsi menggunakan alat Ultrasonik HPLC.Tentukan konsentrasi fasa internal dengan spektrofotometri serapan atom pada $\lambda=242.8$ $n m$.Hitung persen ektraksi emas total pada fasa eksternal dan fasa internal.

\section{HASIL DAN PEMBAHASAN}

\section{Kurva Kalibrasi}

Untuk mengetahui kelinieran antara absorban terhadap konsentrasi larutan standar dibuat kurva kalibrasi. Kurva kalibrasi menggambarkanhubungan antara absorban dengan konsentrasi larutan $\mathrm{Au}$ standar. Konsentrasi larutan $\mathrm{Au}$ standar dibuat $1.0 \mathrm{ppm}$; $2.0 \mathrm{ppm} ; 3.0 \mathrm{ppm} ; 4.0 \mathrm{ppm} ; 5.0 \mathrm{ppm} ; 6.0 \mathrm{ppm}$; $8.0 \mathrm{ppm}$ dan $10 \mathrm{ppm}$. Dari hasil pengukuran didapat kurva seperti pada gambar 2 di bawah ini. Dari kurva tersebut didapat persamaan garis lurus $y=0.0213 x+0.0013$ dan harga koefisien kelinieranya $(\mathrm{R})=0.9963$. Menurut hukum Lambert Beer angka $(\mathrm{R})=0.9963$ memberikan arti bahwa terdapat hubungan yang linier antara absorban dengan konsentrasi Au(III) standar.

\section{Kondisi Optimum}

Dari hasil pengujian kestabilan fasa emulsi pada perbandingan volume antara fasa membran dan fasa internal 1:1 dengan kecepatan pengadukan $1000 \mathrm{rpm}$ merupakan komposisi yang paling stabil. Kestabilan emulsi ditandai dengan tidak terjadinya lagi penurunan tinggi emulsi. Emulsi yang stabil akan mempengaruhi persen ekstraksi emas. Semakin stabil suatu emulsi, semakin tinggi persen ekstraksi emas.

Pengaruh konsentrasi MIBK terhadap persen ekstraksi $\mathrm{Au}$ dapat dilihat pada gambar 4. Persen ekstraksi Au naik pada konsentrasi MIBK 3\% yaitu sebesar $72.03 \%$ dan mengalami penurunan pada konsentrasi MIBK 4\% dan 5\%. Pada konsentrasi 4\% dan 5\% mobilitas Au-MIBK lambat karena molekul MIBK terlalu rapat akibat tingginya konsentrasi, hal ini mengakibatkan kecepatan transpor menurun dan kembalinya MIBK setelah proses stripping ke permukaan fasa organik mengalami hambatan.

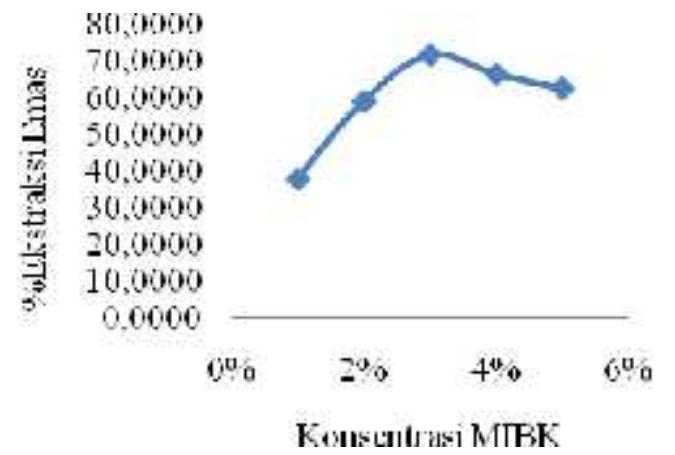

Gambar 4. Pengaruh Konsentrasi MIBK Terhadap Persen Ekstraksi Au

Pada konsentrasi MIBK (Gambar 4) kondisi optimum yaitu $1 \%$ dan $2 \%$, persen ekstraksi Au juga cenderung menurun. Hal ini disebabkan karena MIBK tidak mampu mengkomplekskan semua ion $\mathrm{Au}$ yang ada di fasa umpan. Rendahnya konsentrasi MIBK menyebabkan turunnya mobilitas pembentukan senyawa kompleks dengan ion $\mathrm{Au}(\mathrm{III})$

\section{Kecepatan Kontak Optimal}

Pengaruh kecepatan kontak terhadap persen ekstraksi $\mathrm{Au}(\mathrm{III})$ dapat dilihat pada gambar 5.

Persen ekstraksi mencapai optimum pada kecepatan kontak $400 \mathrm{rpm}$. Hal ini 
disebabkan karena peningkatan kecepatan kontak menjadi 400 rpm, akan meningkatkan kesempatan kontak antara fasa umpan dengan pelarut organik. Dengan demikian tumbukan antara MIBK dengan ion $\mathrm{Au}(\mathrm{III})$ semakin efektif. Akibatnya kompleks Au(III)-MIBK yang terbentuk juga meningkat. Pada peningkatan kecepatan kontak menjadi $600 \mathrm{rpm}$, $800 \mathrm{rpm}$ dan $1000 \mathrm{rpm}$, persen ekstraksi

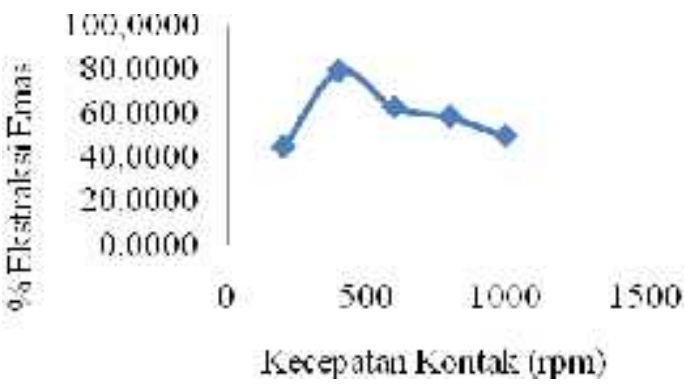

\section{Gambar 5. Pengaruh Kecepatan Kontak Terhadap Persen Ekstraksi Au (III)}

menurun. Penurunan persen ekstraksi ini disebabkan karena terbentuknya emulsi. Kompleks Au(III)-MIBK terperangkap di dalam emulsi dan sulit dikeluarkan.

\section{Kondisi Optimum pada Limbah Papan Sirkuit Telepon Genggam}

Sampel limbah papan sirkuit telepon genggamdi peroleh dari P.T. Nexian dengan ukuran rata-rata panjang $10 \mathrm{~cm}$ dan lebar $6 \mathrm{~cm}$. Sampel diambil bagian interfacenya saja. Dari 10 papan sirkuit diperoleh berat $0.8 \mathrm{~g}$. Sampel kemudian didestruksi menggunakan aquaregia. Sampel yang telah didestruksi menggunakan aquaregia ditambahkan aquades sebanyak 50 $\mathrm{mL}$. Larutan tersebut diukur menggunakan Spektrofotometer Serapan Atom. Dari hasil perhitungan diperoleh konsentrasi emas sebesar $4.6413 \mathrm{ppm}$. Penerapan sampel pada kondisi memberi persen ekstraksi emas sebsear $83.24 \%$ $(\mathrm{w} / \mathrm{w})$

\section{SIMPULAN}

Pada penelitian ini kondisi optimum untuk parameter pembuatan fasa emulsi yaitu 1:1, pengaruh kecepatan pembuatan emulsi pada yaitu $1000 \mathrm{rpm}$.Pengaruh konsentrasi carrier terhadap persen ekstraksi emas dengan konsentrasi MIBK sebesar 3\%, pengaruh kecepatan kontak terhadap persen ekstraksi emas adalah pada 1000 rpm. Ekstraksi logam $\mathrm{Au}(\mathrm{III})$ dari limbah papan sirkuit telepon genggam menggunakan teknik membran cair emulsi memberikan persen ekstraksi sebesar $83.24 \%(\mathrm{w} / \mathrm{w})$

\section{DAFTAR PUSTAKA}

Clayton, W., 1973, Theory of Emulsion, $4^{\text {th }}$ Edition. Philadelphia : The Blakiston Co.

Coelhoso, I.M. dan T.F Moura, 1995, Transport Mechanism in Liqiud Membrane with Ion Exchange Carriers, Journal of Membrane Science., 108: 284-292

Diantoro, Yimi, 2010, Emas, Investasi dan Pengolahannya, Jakarta, PT. Gramedia Pustaka Utama

Guzman L dan Segarra M, 1999, Electrochemistry of Conventional Gold Cyanidation.Journal of Electrochimica Acta., 44(16): 2625-2632.

Haltermann, Johann, 2010, Methyl Isobutyl Ketone Material Safety Data Sheet. Texas, United State, Johann Haltermann Ltd

Kaghazchi, Tahereh dan Ali Kargari, 2004, Role of Emulsifier in Extraction of Gold (III) from Aqueous Solutions using The Emulsion Liquid Membrane Tehnique, Elsevier., 162: 237-247.

Kislik, Vladimir S., 2010, Liquid Membranes, Oxford, Elsevier

Marsden J, House I., 1992, The chemistry of gold extraction, London, UK, Ellis Horwood Ltd

Mok, Y. S., W. K. Lee, and Y. K. Lee, 1997, Modeling of Liquid Emulsion Membranes Facilitated by Two Carriers, Journal of Chem. Eng., 66: 11-20.

Nemeh, I. A., dan A.P.V Peteghem, 1992, Sorbitan Monoleat (Span 80) Decamposition During Membrane Ageing, A Kinetic Study, Journal of Membrane Science., 74: 9-17.

Santoso, Imam, 2009, Separation of Penicillin G from Fermentaion Broth by Emulsion Liquid Membrane Technique, Indo J. Chem., 10(1): 46-50. 

Sofyan, Muhammad, 2010, Limbah Ponsel Mengandung Emas. http://bisnisjabar.com/index.php/2010/11/limbah-ponselmengandung-emas/. 25 Juli 201, pk 21:36

Svehla, G., 1985, Buku Teks Analisis Anorganik Kualitatif Makro dan Semimikro, Edisi ke-5, Jakarta, PT. Kalman Media Pustaka
Widodo, 2008, Pengaruh Perlakuan Amalgamasi Terhadap Tingkat Perolehan Emas dan Kehilangan Merkuri.Jurnal Riset Geologi dan Pertambangan, 1: 47-53. 